\title{
Clinical and Economic Burden of Pediatric Mild-to- Moderate Atopic Dermatitis: A Population-Based Nested Case-Control Study in Sweden
}

\author{
Gustaf Ortsäter (D) · Kirk Geale · Alexander Rieem Dun • \\ Joseph C. Cappelleri · Amy Cha · William Romero • Dan Henrohn • \\ Petra Neregard · Maureen P. Neary
}

Received: October 9, 2020 / Accepted: November 21, 2020 / Published online: December 18, 2020

(C) The Author(s) 2020

\section{ABSTRACT}

Introduction: Atopic dermatitis (AD) is a chronic, relapsing inflammatory skin condition characterized by pruritic, eczematous lesions. Recent evidence suggests that $\mathrm{AD}$ may be a systemic disorder, implying that management

Supplementary Information The online version contains supplementary material available at https:// doi.org/10.1007/s13555-020-00470-z.

G. Ortsäter $(\varangle) \cdot$ K. Geale · A. R. Dun Quantify Research AB, Stockholm, Sweden e-mail: gustaf.ortsater@quantifyresearch.com

K. Geale

Dermatology, Department of Public Health and Clinical Medicine, Umeå University, Umeå, Sweden

J. C. Cappelleri

Global Biometrics and Data Management (Statistics), Pfizer Inc, Groton, CT, USA

A. Cha

Inflammation and Immunology, Pfizer Inc, New

York, NY, USA

W. Romero

Inflammation and Immunology, Pfizer Ltd, London, UK

D. Henrohn · P. Neregard

Inflammation and Immunology, Pfizer $A B$,

Stockholm, Sweden

M. P. Neary

Inflammation and Immunology, Pfizer Inc,

Collegeville, PA, USA of this disease extends beyond merely controlling symptoms associated with $\mathrm{AD}$. Even though this disease is highly prevalent in children and patients typically present with mildto-moderate symptoms, the disease burden is not well established.

Methods: A large, retrospective cohort study of Swedish population data was conducted to compare the clinical burden in terms of healthcare resource use and direct medical costs for pediatric mild-to-moderate (pM2M) AD patients ( $\leq 14$ years of age, $N=87,721$ ) with matched controls. The burden of a severe $\mathrm{AD}$ cohort was also evaluated. Severity of AD was defined by treatment usage and systemic treatment was used as a proxy for severe AD. A robust approach was used by including any type of secondary care visits known to be more common in $\mathrm{AD}$ patients than in the general population; however, data for primary care visits were not available.

Results: For healthcare resource use, the incidence rate ratio (pM2M $\mathrm{AD}$ versus reference cohort) of secondary care visits ranged from 1.56 to 2.35 during each of 5 years after $A D$ onset (all $p<0.001$ ), with largest differences seen in years $1-2$. The average direct medical cost (SD) was $€ 1111$ (3416) and $€ 524$ (2446) in the pM2M AD and reference cohorts, respectively. The corresponding estimate in the severe AD cohort was $€ 1906$ (7067). Including all secondary care visits and pharmacy-dispensed medications, the pM2M AD cohort was shown 
to have an additional $€ 118.9$ million in direct medical costs over 5 years compared with the reference cohort.

Conclusions: This study shows significant clinical and economic burden of pM2M AD with important secondary care resource utilization, suggesting a need for further research to increase treatment options and improve the management of these patients.

Keywords: Atopic dermatitis; Epidemiology; Public health research; Pediatrics

\section{Key Summary Points}

\section{Why carry out this study?}

Even though atopic dermatitis is highly prevalent in children and patients typically present with mild-to-moderate symptoms, the disease burden is not well established.

This study compared the clinical and economic burden for pediatric mild-tomoderate patients with atopic dermatitis.

\section{What was learned from the study?}

Total direct medical costs for pediatric patients with mild-to-moderate atopic dermatitis in Sweden are $€ 118.9$ million higher, cumulatively after 5 years, than in individuals without the disease.

Pediatric mild-to-moderate patients incur substantial clinical and economic burden in secondary care.

\section{DIGITAL FEATURES}

This article is published with digital features to facilitate understanding of the article. You can access the digital features on the article's associated Figshare page. To view digital features for this article go to https://doi.org/10.6084/m9. figshare.13252292.

\section{INTRODUCTION}

Atopic dermatitis (AD) is a chronic, relapsing inflammatory skin condition which manifests as pruritus and eczematous lesions that can be acute, subacute, or chronic [1, 2]. Prevalence of $\mathrm{AD}$ is high across all continents, and approximately $20 \%$ of children and $2-8 \%$ of adults are affected in Western countries [2,3]. Prevalence appears to be increasing in Western Europe $[2,4]$ and seems stable in Northern Europe [5]. In roughly $60 \%$ of cases, $\mathrm{AD}$ manifests during the first year of life (i.e., early onset), but it may start at any age $[6,7]$.

Evidence increasingly suggests that $\mathrm{AD}$ may be a systemic disorder with common inflammatory mechanisms underlying certain comorbid conditions, contributing to the patient and economic burden of $\mathrm{AD}$ [8]. The disease is associated with a wide range of non-allergic comorbid disorders including anxiety, depression, suicidality, attention deficit hyperactivity disorder, and infections [9-12]. Atopic dermatitis is also often considered to be the first clinical manifestation in the "atopic march" which links the disease to subsequent food allergy, rhinitis, and asthma [11, 13]. This means that the true burden of atopic dermatitis may extend well beyond the strictly dermatological spectrum.

Most AD patients have mild-to-moderate disease, whereas approximately $10 \%$ of patients suffer from severe disease [2]. Although disease burden increases with severity [14-16], mild-tomoderate $\mathrm{AD}$ is also associated with substantial patient and economic burden [17]. Evidence regarding the burden of $\mathrm{AD}$ is, however, scarce for mild-to-moderate patients. While a recent systematic review of patient impact and economic burden of mild-to-moderate AD concluded that even mild AD imposed substantial costs and impacted on patient's health-related quality of life, only two studies were European, and the most recent study was published in 2006 [18-20]. Neither of these studies included a control cohort, and they were limited by sample sizes (range 33-474) and follow-up duration (range 3 months -8 years). In another systematic review of economic evidence for 
prevention and treatment of atopic eczema, four additional European studies were identified, but none included stratification by severity [21].

The high prevalence of mild-to-moderate $\mathrm{AD}$, particularly in children, may lead to a high potential for economic burden through health care contacts and prescribed medications. To improve the understanding of the clinical and economic burden for pediatric patients with mild-to-moderate (pM2M) $\mathrm{AD}$, the present study evaluates the clinical burden in terms of healthcare resource use for $\mathrm{AD}$ and the direct medical cost burden over time at the secondary care level. The current study adds to the existing literature by focusing on pediatric mild-tomoderate patients. It also combines complete, nationwide registry data with a long follow-up period and a cohort of reference individuals.

\section{METHODS}

\section{Data and Ethics}

Two population-based Swedish registries, the National Patient Register (NPR), and the Prescribed Drug Register (PDR) were used in this study. Both registers are governed by the Swedish National Board of Health and Welfare and use a common and unique identification number for each individual, enabling patientlevel linkage between registries. The data used in this study were anonymized. This implied that the granularity of certain variables was limited to ensure the anonymity of the patient. Specifically, this meant that the date of secondary care visits and dispensation was provided on a yearly level, age was available in age groups of five (0-4, 5-9, etc.) and Anatomical Therapeutic Chemical (ATC) codes were truncated to a three-digit level.

The NPR contains information on all secondary care (care visits, either outpatient visit or inpatient hospitalization with referral from primary care) in Sweden and data for year of visit, gender, age, and main diagnosis (atopic dermatitis or other diagnosis) were collected for each study participant between 1 January 2001 and 31 December 2017. The PDR contains information on all drug dispensations (originating from both primary and secondary care) filled at pharmacies in Sweden. Data for the ATC code (truncated to three digits), the year of dispensation, and cost of the dispensation for each study participant between 1 July 2005 and 31 December 2017 was collected from the PDR. The cost of dispensed drugs was extracted directly from the PDR which contains the publicly available list prices. All types of dispensed drugs were included in the calculation of total direct medical costs. Cost of drugs was inflated to the 2018 price level using the Swedish consumer price index and then converted into euros using the average exchange rate of SEK/€ during $2018(€ 1=10.31$ SEK). Unit costs of secondary care visits (differentiated between $\mathrm{AD}$ visit and non-AD visit) were extracted from several Swedish regional price lists [22-28] to ensure accurate prices which may vary across regions.

This study was approved by the Regional Ethical Review Board in Gothenburg (Dnr: 2019-02986) and performed in accordance with the ethical standards in the 1964 Declaration of Helsinki and its later amendments. For this type of study, individual formal consent was not required.

\section{Study Population}

This was a retrospective, observational nested case-control study including children aged 0-14 (inclusive) in Sweden with either a primary diagnosis of $\mathrm{AD}$ (ICD-10 code L20+ or L30.8C) in secondary care, or by dispensation of two (within 12 months of each other) topical corticosteroids (TCS), or a topical calcineurin inhibitor (TCI) between 1 January 2009 and 31 December 2017. A schematic outline of the study design is provided in Fig. 1. Patients identified through a dispensation (TCS or TCI) were identified from the PDR which contains all dispensations for primary and secondary care. Hence, patients could be included either through diagnosis code (using the International Classification of Diseases, ICD-10) in secondary care and/or a drug dispensation originating from secondary or primary care. Treatment with 


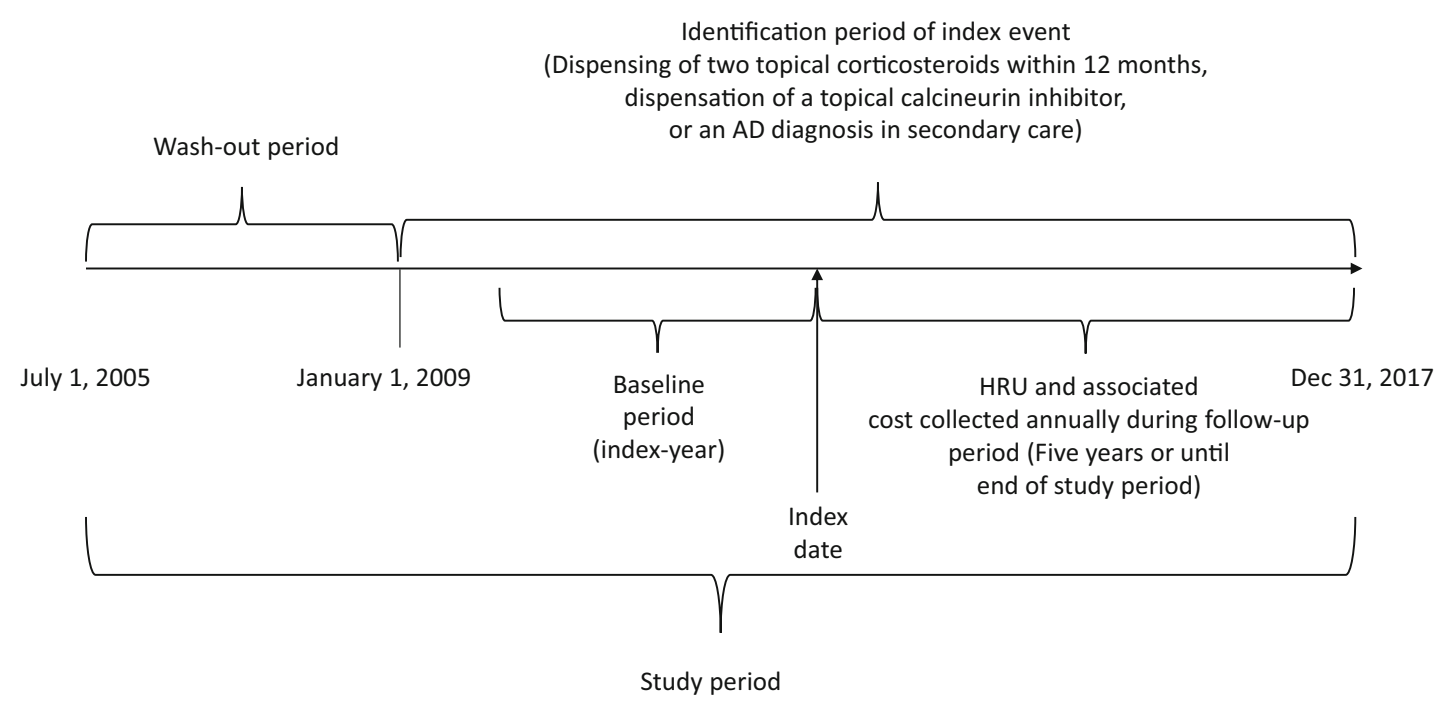

Fig. 1 Study design

TCS drugs is indicated for several skin conditions (including other types of dermatitis and psoriasis), and TCS dispensation alone is a poor predictor of AD diagnosis [29]. Therefore, subjects with hospital visits related to other types of dermatitis or medical conditions known to lead to the use of TCS were excluded from the study population. Diagnosis codes which required exclusion are listed in Table S.I in the supplementary material. In addition to excluding patient-based diagnosis codes to further refine the study population, patients with dispensations of TCSs used in other types of dermatitis or to treat vaginal fungal infection, antipsoriatics or salicylates for dermatological use were also excluded from the study population. ATC codes which required exclusion are listed in Table S.II. The exclusion algorithm used in this study was based on a previously published study in Sweden [5]. This study used the European classification system for the potency of corticosteroids which includes four levels (I-IV) in ascending order of potency [30].

As severity of the disease is not coded in administrative registers, this study defined severity based on concurrent treatment employed in a previously published study [31]. Patients with systemic treatments (corticosteroids and non-corticosteroid immunosuppressants) were considered to have a severe form of $\mathrm{AD}$ and are presented separately in this publication for reference [31].

The pM2M AD cohort was matched by age and gender to a random sample (reference cohort) from the Total Population Register held by Statistics Sweden. The register covers the entire Swedish population from 1968 and contains basic demographic and socioeconomic information on the individual level. In this study, the register was only used to identify the reference cohort and no information was extracted. The two cohorts (the pM2M AD and reference cohort) were mutually exclusive and had equal lengths of follow-up.

\section{Study Design}

The date of inclusion was selected as the patient's index date and is a proxy for the start of clinically diagnosed $\mathrm{AD}$ or a new episode with AD-care visits and/or treatment (after a look-back period of at least 3.5 years without treatment in primary or secondary care and/or a secondary care visit due to AD). Patients were followed from index date until the end of study period on 31 December 2017. Date of death was not available in this study and thus not controlled for. Each reference individual was allocated the same index date as their matched case. This implied that each case and 
corresponding reference had identical followup. Demographic characteristics and treatment type (case cohort) were described at the index date.

\section{Statistical Analyses}

Healthcare resource use was observed annually from index date until the end of the study period. All secondary care visits (AD- and nonAD-related) were included, and the incidence rate ratio (IRR) of secondary care visits between the pM2M AD cohort and reference cohort was calculated annually by dividing the number of secondary care visits per year in the pM2M AD cohort by the number in the reference cohort. Total direct medical costs, including cost of all $\mathrm{AD}$-related and non-AD-related secondary care visits and dispensed drugs were calculated annually in all cohorts. The cost of secondary care visits was calculated by multiplying each secondary care visit by one of the following costs: $€ 275$ per AD-related outpatient visit, $€ 279$ per non-AD-related outpatient visit, $€ 546$ per day of AD-related inpatient hospitalization, and $€ 661$ per day of non-AD-related inpatient hospitalization. A visit was considered AD-related if the primary diagnosis was either L20+ or L30.8C. Cost of dispensed drugs was extracted directly from the PDR.

The number $(n)$, mean, and standard deviation (SD) were presented for continuous variables while the number and percentage were presented for categorical variables. Comparisons between the pM2M AD and the reference cohort were evaluated using statistical tests with an a priori significance level of alpha $=0.05$. An independent two-group $t$ test was used to compare means for continuous variables, and a chisquare test to compare proportions for categorical variables [32]. Statistical comparisons were made within years between patients and reference individuals, but comparisons across years were not performed. All analyses were performed in Stata (StataCorp. 2019. Release 16. College Station, TX, USA: StataCorp LLC.).

\section{RESULTS}

\section{Patient Characteristics and Clinical Burden}

A total of 99,300 patients were included in the two case cohorts through a secondary care diagnosis of $\mathrm{AD}$, a TCS dispensation, and/or a TCI dispensation according to previously used criteria [5]. Of these, $11.7 \%(11,609)$ received systemic treatments during the study period and were deemed to have severe $\mathrm{AD}$. The remaining 87,721 patients were considered to have mild-to-moderate AD. An equal number $(87,721)$ of reference individuals were included in the reference cohort.

Baseline characteristics for the mild-to-moderate cohort, the severe $\mathrm{AD}$ cohort, and the reference cohort at index date are presented in Table 1 . At index date, $67.5 \%$ of pM2M were between 0 and 4 years old, and $53.2 \%$ were male. In the severe subgroup, patients were older, and $57.6 \%$ were male. A majority of $\mathrm{AD}$ patients were identified through a TCS dispensation, $89.1 \%$ and $89.7 \%$ in the $\mathrm{pM} 2 \mathrm{M}$ and severe $\mathrm{AD}$ cohort, respectively.

\section{Healthcare Resource Use}

The pM2M AD cohort had a larger number of secondary care visits (for any reason) on average than the reference cohort during all years of follow-up. In the index year, the average number (SD) of all secondary care visits was 2.25 (3.36) and 0.96 (2.14) per patient in the pM2M $\mathrm{AD}$ and reference cohort, respectively (Fig. 2). Most secondary care visits were outpatient visits $(94.5 \%)$, while hospitalizations were uncommon (5.5\%). The severe AD cohort had on average 3.14 (6.16) secondary care visits in the index year. The largest IRR between the pM2M $\mathrm{AD}$ cohort and the reference cohort was found in the first two years (2.35 and 1.91, respectively) following index and ranged between 1.56 and $2.35(P<0.001)$ for up to $1-5$ years after disease onset. Similarly, the average number of drug dispensations (any drug) was also larger in the pM2M AD cohort compared with the reference cohort throughout the follow-up. During the index year, the pM2M AD cohort 
Table 1 Patient characteristics at index date

\begin{tabular}{|c|c|c|c|}
\hline & Pediatric mild-to-moderate cohort & Pediatric severe cohort & Reference cohort \\
\hline Number of unique patients & 87,721 & 11,609 & 87,721 \\
\hline \multicolumn{4}{|l|}{ Age group } \\
\hline $0-4$ & $59,192(67.5 \%)$ & $6556(56.5 \%)$ & $59,192(67.5 \%)$ \\
\hline $5-9$ & $17,469(19.9 \%)$ & $2836(24.4 \%)$ & $17,469(19.9 \%)$ \\
\hline $10-14$ & $11,060(12.6 \%)$ & $2217(19.1 \%)$ & $11,060(12.6 \%)$ \\
\hline \multicolumn{4}{|l|}{ Gender } \\
\hline Female & $41,036(46.8 \%)$ & $4922(42.4 \%)$ & $41,036(46.8 \%)$ \\
\hline Male & $46,685(53.2 \%)$ & $6687(57.6 \%)$ & $46,685(53.2 \%)$ \\
\hline \multicolumn{4}{|l|}{ Treatment type at index date ${ }^{a}$} \\
\hline $\mathrm{TCS}^{\mathrm{b}}$ & $78,122(89.1 \%)$ & $10,416(89.7 \%)$ & \\
\hline $\mathrm{TCI}^{\mathrm{c}}$ & $1758(2.0 \%)$ & $318(2.7 \%)$ & \\
\hline No treatment ${ }^{\mathrm{d}}$ & $9056(10.3 \%)$ & $1106(9.5 \%)$ & \\
\hline
\end{tabular}

received on average 12.50 pharmacy dispensations per patient while reference individuals on average received 3.39 pharmacy dispensations per patient (data not shown). Patients in the severe $\mathrm{AD}$ cohort received on average 17.90 dispensations in the index year. The mean difference in healthcare resource use (both in terms of secondary care visits and dispensed drugs) between the pM2M AD and the reference cohort was statistically significant $(P<0.001)$ in all years. Detailed statistics are reported in Table S.III in the supplementary material section.

\section{Direct Medical Costs}

Given the larger healthcare resource use in the pM2M AD cohort, direct medical costs were consequently also larger in the pM2M AD cohort compared with the reference cohort. During the index year, the average direct medical costs were $€ 587$ higher per patient in the pM2M AD cohort compared with that for patients in the reference cohort. The average direct medical cost (SD) in the pM2M AD cohort was $€ 1111$ (3416), and $€ 524$ (2446) in the reference cohort. The corresponding estimate in the severe AD cohort was $€ 1906$ (7067). The cost of secondary care visits for patients in the pM2M AD cohort ( $€ 428$ per patient) represented $73 \%$ of the incremental direct medical costs, while the cost of dispensed drugs ( $€ 159$ per patient) represented the remaining $27 \%$. Five years following index date, the cumulative difference in total direct medical costs was $€ 118.9$ million ( $€ 1663$ per patient) for the entire pM2M cohort. Detailed statistics are reported in Table S.IV in the supplementary material section.

\section{DISCUSSION}

This large, retrospective, observational study identified a significant clinical and economic burden in patients with mild-to-moderate $\mathrm{AD}$ 




Fig. 2 Average number of yearly secondary care visits per patient (AD- and non-AD-related), by year after index. The error bars represent $95 \%$ confidence intervals

treated at the secondary care level. Economically, direct medical costs were $€ 1663$ higher per patient over 5 years. At a population level in Sweden, a country with 10 million inhabitants, this translates to an aggregate (excess) societal economic burden of $€ 118.9$ million. Given the high prevalence of $\mathrm{AD}$ worldwide, this study provides important data on the clinical and economic burden of this common skin disease $[5,18,33]$.

A decline in secondary healthcare resource use following index date was observed in the present study and may indicate that patients' symptoms improved over time, potentially through successful treatment regimens or spontaneous resolution of the disease in some patients. However, a recent study [34] shows that disease persistence is high and that the decline in healthcare resource use may be a consequence of patients being returned to primary care for continuous management (and thus are not captured in the present study). The evolution of costs over time suggests that healthcare resource use is the most intense in the short term after onset of the disease or at relapse of symptoms.

\section{Comparison with Previous Studies}

The cost burden of pM2M AD patients reported across other studies varies substantially (between $€ 49$ and $€ 1519$ ), likely due to differences in study design (retrospective, prospective, and survey), study setting (inclusion of reference cohort), and type of cost (drugs, primary and secondary care visits, out-of-pocket expenses, indirect costs). These differences make comparisons between studies difficult. The estimated cost burden of pM2M AD in the present study appears to be within the range of cost burden reported in the published literature. A German study that included children used a similar study design as the present study (retrospective with 8-year follow-up), and reported an average annual cost for AD of $€ 194$ in mild patients and $€ 417$ in moderate patients [20]. The average annual cost per patient (over 5 years) in the present study was $€ 224$. Another 
retrospective study in a French setting reported the average cost of medications per patient used during the first year of follow-up to be $€ 175$ in the eczema cohort compared with $€ 99$ in the reference individuals. The average cost of dispensed drugs in this study was $€ 225$ and $€ 67$ per patient in the pM2M AD cohort and reference cohort, respectively [35]. Two Nordic studies (survey and prospective study) included cost of primary and secondary care visits together with cost of medications [36] and indirect cost [37], but neither differentiated results by severity. The survey study estimated the incremental cost of patients experiencing eczema symptoms at $€ 410$, while the prospective study estimated the incremental cost at $€ 291$. Finally, an Italian survey reported an annual average cost of $€ 900$ in mild patients and $€ 1519$ in moderate patients [19].

\section{Strengths and Limitations}

A major strength of this study is the use of two large national databases with complete population-level coverage to identify the study population. This study, therefore, provides a complete account of healthcare resource use in secondary care and for dispensed drugs originating from both primary and secondary care.

Further, through the use of these national databases with long follow-up, it was possible to identify a large study population of pM2M AD patients for inclusion in this study $(N=87,721)$. At the same time, we used a look-back period of at least 3.5 years which increases the likelihood that the index date represents the initiation of newly clinically managed $\mathrm{AD}$ rather than a relapse of this chronic disease. Additionally, a matched reference cohort (non-AD) was identified from the national population register to allow for comparisons.

Three key factors contribute to possible bias in the study results. First, initial contact with the healthcare services in Sweden for mild, nonacute diseases is often in primary care. The present study collected primary care data for dispensed medications but not for diagnoses. Therefore, the complete economic burden of mild-to-moderate $\mathrm{AD}$ is likely higher than estimated in this study since this study does not include the cost of primary care visits and most patients with mild-to-moderate atopic dermatitis are treated by primary care physicians.

Second, the date for first dispensation of a TCS/TCI or a diagnosis in secondary care was used as the index date rather than the date of primary care diagnosis. This means that patients treated solely with emollients or lowest-potency TCS medications were not included in this study since these agents are available as overthe-counter drugs in Sweden and hence not captured by the PDR. From this perspective, the results in this study may therefore overestimate the economic burden since these "mildest" mild-to-moderate patients are likely to incur less than average healthcare resource use compared with the average mild-to-moderate $\mathrm{AD}$ patient. On the other hand, emollients are the basis of treatment for $\mathrm{AD}$ in all severities and the cost of these is not captured by this study.

Third, severity based on clinical assessment was not available in the administrative registers used in this study. Therefore, the definition of mild-moderate and severe $\mathrm{AD}$ was based on treatment class (topical, systemic, phototherapy) where information on potency and treatment concentrations was not available. This may have led to misclassification as we could not distinguish drugs with respect to potency within the class of TCS or concentrations within the class of TCIs since we only had access to the first three digits of the ATC codes in the database. Additionally, misclassification may have occured as mild-to-moderate patients with a flare may have been treated temporarily with systemic treatments or may have received phototherapy (this was not available in the database), or severe patients may not have received systemic treatment for unknown reasons. Although it was not possible to validate the severity classification, it follows treatment guidelines and the percentage of severe patients in this study $(11.7 \%)$ is in line with other studies [2].

In addition, date of death was not included in this study, and therefore patients were not censored at death. Since the study population consisted of pediatric patients, this likely had a minor impact on the study results. In addition, 
this study only accounted for direct health care costs and did not include other types of costs, such as indirect costs associated with loss of school days. Finally, another limitation in this study was the inability to verify the sensitivity and specificity of the inclusion and exclusion criteria employed to identify $\mathrm{AD}$ cases from prescription data. However, the algorithm used in this study was developed by specialists in dermatology, pharmacoepidemiology, and biostatistics and has been validated in a Danish setting, yielding a sensitivity and specificity of $74.1 \%$ and $73.0 \%$, respectively [38].

\section{CONCLUSION}

We evaluated and compared the clinical and economic burden for a population of 87,721 pediatric patients with mild-to-moderate $\mathrm{AD}$ to that of a randomly selected reference cohort using longitudinal, population-based data in Sweden. We also evaluated the clinical and economic burden in a severe AD cohort.

In the seldom-studied patient group of mildto-moderate $\mathrm{AD}$, the cumulative excess (direct) societal economic burden of AD was substantial, conservatively estimated to be $€ 118.9$ million after 5 years. Albeit the average direct medical costs per patient was higher in the severe $\mathrm{AD}$ cohort, the societal economic burden of mild-to-moderate $\mathrm{AD}$ is higher due to the high prevalence. The annual differences in costs between patient and reference cohorts were observed to be largest close to time of disease identification. This estimate includes the robust approach of including not only direct AD-related visits, but also any type of secondary care visits known to be more common in $\mathrm{AD}$ patients than in the general population. The clinical and economic burden identified in this study, especially the high use of secondary care resources in pediatric patients with mild-tomoderate disease suggests a need for further research to increase treatment options and improve the management of pediatric $\mathrm{AD}$ patients with mild-to-moderate disease.

\section{ACKNOWLEDGEMENTS}

The authors of this study would like to thank Prof. Jacob Thyssen and Drs. Natalia Ballardini and Anna De Geer for their comments and input that greatly improved this manuscript.

Funding. This study was sponsored by Pfizer Inc. The Rapid Service Fee was funded by Quantify Research AB.

Authorship. All authors meet the International Committee of Medical Journal Editors (ICMJE) criteria for authorship for this manuscript, take responsibility for the integrity of the work as a whole, and have provided final approval of the version to be published.

Medical Writing and Editorial Assistance. Editorial and medical writing support under the guidance of authors was provided by Mathias Lilja of Quantify Research AB, and was funded by Pfizer Inc, in accordance with Good Publication Practice (GPP3) guidelines (Ann Intern Med. 2015;163:461-464).

Disclosures. Amy Cha, Joseph C. Cappelleri, and Maureen P. Neary are employed by Pfizer Inc. and own Pfizer stock and/or stock options. William Romero is employed by Pfizer Ltd and owns Pfizer stock and/or stock options. Dan Henrohn and Petra Neregard are employed by Pfizer AB and own Pfizer stock. Kirk Geale is an employee and board member of Quantify Research and owns Quantify Research stock options. Gustaf Ortsäter and Alexander Rieem Dun are employed by Quantify Research AB. Quantify Research AB provides consulting and other research services to pharmaceutical, medical device, and related organizations. Quantify Research $\mathrm{AB}$ received funding from Pfizer Inc. to conduct this study and for the development of this manuscript.

Compliance with Ethics Guidelines. This study was approved by the Regional Ethical Review Board in Gothenburg (Dnr: 2019-02986) and performed in accordance with the ethical standards in the 1964 Declaration of Helsinki 
and its later amendments. For this type of study, individual informed consent was not required.

Data Availability. The datasets generated during and/or analyzed during the current study are protected under Swedish and European law and may only be accessed following relevant ethical approvals, data protections assessments, and compliance with GDPR.

Open Access. This article is licensed under a Creative Commons Attribution-NonCommercial 4.0 International License, which permits any non-commercial use, sharing, adaptation, distribution and reproduction in any medium or format, as long as you give appropriate credit to the original author(s) and the source, provide a link to the Creative Commons licence, and indicate if changes were made. The images or other third party material in this article are included in the article's Creative Commons licence, unless indicated otherwise in a credit line to the material. If material is not included in the article's Creative Commons licence and your intended use is not permitted by statutory regulation or exceeds the permitted use, you will need to obtain permission directly from the copyright holder. To view a copy of this licence, visit http://creativecommons.org/licenses/bync/4.0/.

\section{REFERENCES}

1. Weidinger S, Novak N. Atopic dermatitis. Lancet. 2016;387(10023):1109-22.

2. Wollenberg A, Barbarot S, Bieber T, Christen-Zaech S, Deleuran M, Fink-Wagner A, et al. Consensusbased European guidelines for treatment of atopic eczema (atopic dermatitis) in adults and children: part I. J Eur Acad Dermatol Venereol. 2018;32(5): 657-82.

3. Bylund S, von Kobyletzki LB, Svalstedt M, Svensson A. Prevalence and incidence of atopic dermatitis: a systematic review. Acta Derm Venereol. 2020;100(12):adv00160.

4. Deckers IAG, McLean S, Linssen S, Mommers M, van Schayck $C P$, Sheikh A. Investigating international time trends in the incidence and prevalence of atopic eczema 1990-2010: a systematic review of epidemiological studies. PLoS ONE. 2012;7(7): e39803.

5. Henriksen L, Simonsen J, Haerskjold A, Linder M, Kieler $\mathrm{H}$, Thomsen SF, et al. Incidence rates of atopic dermatitis, asthma, and allergic rhinoconjunctivitis in Danish and Swedish children. J Allergy Clin Immunol. 2015;136(2):360-366e2.

6. Illi S, von Mutius E, Lau S, Nickel R, Grüber C, Niggemann B, et al. The natural course of atopic dermatitis from birth to age 7 years and the association with asthma. J Allergy Clin Immunol. 2004;113(5):925-31.

7. Garmhausen D, Hagemann T, Bieber T, Dimitriou I, Fimmers R, Diepgen $\mathrm{T}$, et al. Characterization of different courses of atopic dermatitis in adolescent and adult patients. Allergy. 2013;68(4):498-506.

8. Brunner PM, Silverberg JI, Guttman-Yassky E, Paller AS, Kabashima K, Amagai $M$, et al. Increasing comorbidities suggest that atopic dermatitis is a systemic disorder. J Invest Dermatol. 2017;137(1): $18-25$.

9. Silverberg JI. Comorbidities and the impact of atopic dermatitis. Ann Allergy Asthma Immunol. 2019;123(2):144-51.

10. Silverberg JI, Gelfand JM, Margolis DJ, Boguniewicz $\mathrm{M}$, Fonacier L, Grayson $\mathrm{MH}$, et al. Association of atopic dermatitis with allergic, autoimmune, and cardiovascular comorbidities in US adults. Ann Allergy Asthma Immunol. 2018;121(5):604-612e3.

11. Andersen YMF, Egeberg A, Skov L, Thyssen JP. Comorbidities of atopic dermatitis: beyond rhinitis and asthma. Curr Dermatol Rep. 2017;6(1):35-41.

12. Riis JL, Vestergaard C, Deleuran MS, Olsen M. Childhood atopic dermatitis and risk of attention deficit/hyperactivity disorder: a cohort study. J Allergy Clin Immunol. 2016;138(2):608-10.

13. Bantz SK, Zhu Z, Zheng T. The atopic march: progression from atopic dermatitis to allergic rhinitis and asthma. J Clin Cell Immunol. 2014;5(2):67-73.

14. Monti F, Agostini F, Gobbi F, Neri E, Schianchi S, Arcangeli F. Quality of life measures in Italian children with atopic dermatitis and their families. Ital J Pediatr. 2011;37:59.

15. Torrelo A, Ortiz J, Alomar A, Ros S, Pedrosa E, Cuervo J. Health-related quality of life, patient satisfaction, and adherence to treatment in patients with moderate or severe atopic dermatitis on maintenance therapy: the CONDA-SAT study. Actas Dermosifiliogr. 2013;104(5):409-17. 
16. Andersen L, Nyeland ME, Nyberg F. Increasing severity of atopic dermatitis is associated with a negative impact on work productivity among adults with atopic dermatitis in France, Germany, the UK and the US. Br J Dermatol. 2020;182(4): 1007-16.

17. Ballardini N, Ostblom E, Wahlgren CF, Kull I. Mild eczema affects self-perceived health among preadolescent girls. Acta Derm Venereol. 2014;94(3): 312-6.

18. Hebert AA, Stingl G, Ho LK, Lynde C, Cappelleri JC, Tallman AM, et al. Patient impact and economic burden of mild-to-moderate atopic dermatitis. Curr Med Res Opin. 2018;34(12):2177-85.

19. Ricci G, Bendandi B, Pagliara L, Patrizi A, Masi M. Atopic dermatitis in Italian children: evaluation of its economic impact. J Pediatr Health Care. 2006;20(5):311-5.

20. Weinmann S, Kamtsiuris P, Henke KD, Wickman $M$, Jenner A, Wahn U. The costs of atopy and asthma in children: assessment of direct costs and their determinants in a birth cohort. Pediatr Allergy Immunol. 2003;14(1):18-26.

21. Sach TH, McManus E, Levell NJ. Understanding economic evidence for the prevention and treatment of atopic eczema. Br J Dermatol. 2019;181(4): 707-16.

22. Karolinaska universitetssjukhuset. Prislista för utomlänsvård samt för EU/EES och Schweiz 2018. 2018. http://www.sthlm-gotland.se/wp-content/up loads/2017/11/Bilaga-2-Utoml\%C3\%A4nsprislistaKarolinska-Universitetssjukhusets-2018.pdf. Accessed May 2019.

23. Landstinget i Uppsala län. PRIS-OCH PRODUKTKATALOG 2018, Akademiska Sjukhuset ,Lasarettet i Enköping. 2018. http://svnuppsalaore bro.se/3-styrande/prislistor/2018/Uppsala_201807 01.pdf. Accessed May 2019.

24. Region Dalarna. Tjänstekatalog-Hjälpmedel Dalarna. 2019. https://www.regiondalarna.se/cont entassets/5fe937b3e18e41b1b8af0862e2f33577/bil aga-8-a-prislista-dalarnas-kommuner-och-region-da larna.pdf. Accessed May 2019.

25. Region västmanland. Utomlänsprislista Region Västmanland 2018. 2018. http://svnuppsalaorebro. se/3-styrande/prislistor/2018/Vastmanland_2018. pdf. Accessed May 2019.

26. Samverkansnämnden. Priser och ersättningar för sydöstra sjukvårdsregionen 2018. 2017. https:// plus.rjl.se/info_files/infosida41089/prislista_2018. pdf. Accessed May 2019.
27. SJUKVÅRDSREGIONEN V, Samverkansnämnden. Utomlänspriser 2018 För vårdtjänster enligt samverkansavtal om hälso-och sjukvård inom Västra sjukvårdsregionen. 2018. https://alfresco.vgre gion.se/alfresco/service/vgr/storage/node/content/ workspace/SpacesStore/ebb87355-c799-48c1-86e2a6d2421d69b7/Utoml\%C3\%A4nsprislista\%202018. pdf?a=false\&guest=true. Accessed May 2019.

28. Södra sjukvårdsregion. Regionala priser och ersättningar föregående år. 2018. https://sodrasjukv ardsregionen.se/verksamhet/avtal-priser/regionalapriser-och-ersattningar-foregaende-ar/. Accessed May 2019.

29. Ortqvist AK, Lundholm C, Wettermark B, Ludvigsson JF, Ye W, Almqvist C. Validation of asthma and eczema in population-based Swedish drug and patient registers. Pharmacoepidemiol Drug Saf. 2013;22(8):850-60.

30. Badoi S. Committee of experts on the classification of medicines as regards their supply. 2016. https:// www.edqm.eu/sites/default/files/cd-p-ph-pho_progra mme_results_2016-17.pdf. Accessed Feb 2020.

31. Eichenfield LF, DiBonaventura M, Xenakis J, Lafeuille MH, Duh MS, Fakih I, et al. Costs and treatment patterns among patients with atopic dermatitis using advanced therapies in the United States: analysis of a retrospective claims database. Dermatol Ther (Heidelb). 2020;10(4):791-806.

32. Rosner B. Fundamentals of biostatistics. 8th ed. Cengage Learning; 2015.

33. Theodosiou G, Montgomery S, Metsini A, Dalgard FJ, Svensson A, Kobyletzki LB. Burden of atopic dermatitis in Swedish adults: a population-based study. Acta Derm Venereol. 2019;99(11):964-70.

34. Thyssen JP, Corn G, Wohlfahrt J, Melbye M, Bager P. Retrospective markers of paediatric atopic dermatitis persistence after hospital diagnosis: a nationwide cohort study. Clin Exp Allergy. 2019;49(11):1455-63.

35. Misery L, Ansolabehere X, Grandfils N, Georgescu $\mathrm{V}$, Taieb C. Nine-year follow-up of children with atopic dermatitis by general practitioners. Dermatology. 2014;228(4):344-9.

36. Hammer-Helmich L, Linneberg A, Thomsen SF, Tang L, Glumer C. Health service use among children with and without eczema, asthma, and hay fever. Clin Epidemiol. 2016;8:341-9.

37. Alanne S, Maskunitty A, Nermes M, Laitinen K, Pekurinen M. Costs of allergic diseases from birth to two years in Finland. Public Health. 2012;126(10): 866-72. 
38. Stensballe LG, Klanso L, Jensen A, Haerskjold A, Thomsen SF, Simonsen J. The validity of register data to identify children with atopic dermatitis,

asthma or allergic rhinoconjunctivitis. Pediatr Allergy Immunol. 2017;28(6):535-42. 